\title{
INTERCONEXÃO ENTRE POLÍTICAS EDUCACIONAIS E ESPAÇO GEOGRÁFICO
}

Eduardo Cesar da Costa ${ }^{1}$

Adriana Maria Andreis ${ }^{2}$

Universidade Federal da Fronteira Sul

Recibido 09/06/2021 Aceptado 04/10/2021

As dimensões continentais e as desigualdades sociais brasileiras latentes envolvem toda política pública, especialmente, as relacionadas com a educação escolar. Trata-se de um desafio complexo, pois as diversidades do espaço geográfico são marcantes. Considerando esse contexto problematizador, o objetivo deste artigo, é compreender as inter-relações entre o espaço geográfico e as políticas educacionais brasileiras. Justifica-se, pois as deliberações documentais influenciam e são influenciadas pela realidade dos lugares, como tem se evidenciado no contexto da pandemia da COVID-19. O artigo está organizado na modalidade de ensaio teórico, baseado na discussão documental de políticas educacionais em diálogo com estudos das áreas de Geografia e Educação.

5 The continental dimensions and the latent social inequalities in Brazil involve all kinds of public policies, especially those related to school education. This is a complex challenge, since the diversities of the geographic space are remarkable. Considering this problematizing context, the objective of this article is to understand the interrelations between geographic space and Brazilian educational policies. It is justified because the document deliberations influence and are influenced by the reality of places, as has been evidenced in the context of the COVID-19 pandemic. The article is organized in the modality of theoretical essay, based on the documental discussion of educational policies in dialogue with studies from the areas of Geography and Education.

DOI

https://doi.org/10.15366/didacticas2021.25.008

PALABRAS CLAVE

Espaço Geográfico Coetâneo; Educação; Geografia; Políticas Educacionais.

Coetaneous Geographic Space; Education; Geography; Educational Policies. 


\section{INTRODUÇÃO}

A política educacional brasileira se organiza a partir de uma série de documentos, legis lações, planos e programas, que se articulam entre si para atender os objetivos e metas previstos no conjunto de políticas. Em diálogo com este complexo, a ciência geográfica se dedica à compreensão dos fenômenos e dinâmicas do espaço geográfico, seus sistemas de ações e objetos em constante reconstrução. Portanto, cabe também à Geografia o compromisso de debater e estudar, por meio de seus conceitos articuladores, as relações intrínsecas entre a realidade do espaço geográfico e as políticas educacionais.

A pandemia da COVID-19 que se instaurou no mundo e no Brasil, marcadamente ainda no início de 2020, transformou a realidade do espaço e das relações sociais, impondo à sociedade brasileira inúmeros desafios e adequações. Considere-se que, nesse conjunto imposto pela pandemia, o país tem especificidades caracterizadas pelas diversidades, relacionadas: com a sua extensão territorial, com a concentração extrema de riquezas paralelas à pobreza de parcela significativa da população e dificuldades de acesso aos sistemas informacionais, entre outros fatores. No campo educacional explicitou a importância de que as políticas educacionais contemplem e se adequem às realidades singulares e às necessidades específicas dos heterogêneos lugares, que são compositores da totalidade do espaço. Também explicitou a interinfluência exercida entre as políticas educacionais e o espaço geográfico coetâneo, considerando a realidade educacional brasileira múltipla e complexa.

Em um país de amplitude continental como o Brasil, e que é constituído por uma heterogeneidade de sujeitos e lugares, torna-se imprescindível reconhecer e compreender a relação inescapável de confroencontro ${ }^{1}$ (Andreis, 2014) constitutivo entre política educacional e espaço geográfico. Assim, buscaremos neste ensaio debater possíveis compreensões a questionamentos que envolvem as noções de políticas educacionais e espaço geográfico, tendo como horizonte a resposta à pergunta: Como a política educacional brasileira interfluencia-se com o espaço geográfico?

A relevância desta pesquisa habita na clareza da conexão entre política educacional e espaço geográfico, que é fundamental ao reconhecimento da relevância da vida escolar. $\mathrm{O}$ objetivo desta investigação é compreender as vinculações entre as políticas educacionais brasileiras e o espaço geográfico, visibilizando, assim, que as deliberações documentais influenciam e são influenciadas pela realidade. Buscamos contribuir na compreensão da relevância e importância de considerar as especificidades dos lugares para uma maior assertividade de políticas educacionais. Se justifica, ainda, pela carência de pesquisas acadêmicas empenhadas em realizar esta associação teórico-conceitual.

1 "Confroencontro é um termo cunhado para configurar o entendimento da sempre presença de confronto em todo encontro (confro + encontro), argumentado como processo inerente à perspectiva dialógica" (Andreis, 2014, p. 19) 
Metodologicamente este texto se apresenta como um ensaio teórico. Tendo como horizonte as interrogações que movem esta pesquisa, aporta-se em alguns estudos de pesquisadores da área de Geografia, como Massey (2008) e Santos (2006), e do campo das Políticas Educacionais como Souza (2016), Melazzo (2010), Maar (2017), e Mainardes (2018). Destacamos que este ensaio teórico se desdobra a partir do projeto de pesquisa intitulado "Política educacional brasileira e a coetaneidade do espaço geográfico: a Base Nacional Comum Curricular (BNCC) no contexto da pandemia Covid-19", financiado pela Universidade Federal da Fronteira Sul (Edital no 381/GR/UFFS/2020), e coordenado pela Professora Dra Adriana Maria Andreis.

Este ensaio está organizado em quatro partes, sendo a primeira dedicada a explicar conceitualmente o que é política, política pública e política educacional, bem como apresentar como esta dinâmica se apresenta na realidade brasileira. Na segunda parte, trazemos algumas concepções teórico-conceituais de espaço geográfico coetâneo e sua relação com a realidade múltipla efetivada no lugar e no cotidiano dos diferentes sujeitos. $\mathrm{Na}$ terceira parte, propomos um exercício de imaginação envolvendo um fragmento multies calar e multirrelacional de um lugar e um cotidiano do espaço geográfico, considerando elos conceituais da Geografia. Na seção seguinte, apresentamos uma discussão acerca de como este confroencontro entre as políticas públicas educacionais e o espaço geográfico se materializam promovendo resultados e consequências no lugar escolar.

\section{POLITICA PÚBLICA EDUCACIONAL BRASILEIRA}

Para que possamos debater as relações entre as políticas educacionais e o espaço geográfico, faz-se necessária uma abordagem conceitual sobre os dois campos em estudo neste ensaio. Deste modo, nesta seção buscamos apresentar algumas concepções sobre política, políticas públicas e políticas educacionais, e como estas concepções se concretizam no Brasil.

Com o estabelecimento das relações humanas em sociedades organizadas em Estados, torna-se importante a criação de ferramentas que auxiliem na resolução de conflitos e na organização da vida social. Deste modo, a política, serve como uma ferramenta mediadora dos conflitos sociais e de disputas por poder, além de organizar as ações de uma sociedade. Ao encontro desta questão, Maar (2017, p. 07), propõe que "A política surge [...] com o dinamismo de uma realidade em constante transformação que continuamente se revela insuficiente e insatisfatória e que não é fruto do acaso, mas resulta da atividade dos próprios homens vivendo em sociedade." Essas interações têm implicações relacionadas com a noção de território no sentido de que envolvem forças de propriedade e apropriação, articulando-se a diferentes concepções de política. Em geral estão atreladas à noção de poder, conforme discutem alguns estudiosos, como por exemplo Lacoste (2005), Weber (1970), Maquiavel (1996) e Foucault (2008). Conquistas, mudanças, recorrências e 
manutenções, como permite entender Souza (2016), envolvem esse complexo constitutivo da política educacional.

Neste sentido Melazzo (2010, p. 11), apresenta diferentes possibilidades de conceituar política. Aponta que "[...] pode ser compreendido enquanto ciência dos fenômenos referentes ao Estado ou ao Governo". Também, indica ser o "[...] sistema de regras que dizem respeito à direção dos negócios e à administração pública.” Nesta mesma linha, o pesquisador aponta que se trata da "arte de governar os povos, ou ainda, [...] refere-se ao poder, resolução de conflitos ou mecanismos de tomadas de decisão." Além disso, Mellazo propõe que "Outra linha de análise nos remete ao ato de pessoas ou grupos de pessoas se fazerem presentes e participantes de atividades que visem transformar ou manter uma certa realidade $[. .$.$] ", e ressalta que estão "[...] sempre localizadas em um espaço geográfico e$ histórico, que pressupõe movimento e constante renovação.” Os entendimentos conceituais do estudioso, permitem inferir as diversas possibilidades de realização da política na realidade. Também, nos apontam alguns indícios de como essa se manifesta na vida social cotidiana, estando sempre atrelada a uma disputa por poder, que se concretiza em um determinado espaço e tempo que está em constante transformação.

Maar (2017) analisa que a política se manifesta no cotidiano dos indivíduos de duas maneiras diferentes e inter-relacionadas, sendo uma por meio da interação com a esfera político institucional e outra nas relações sociais cotidianas. A esfera política institucional é composta pelo conjunto de organismos e regulações de Estado, como os poderes executivo, legislativo e judiciário, e as legislações. A política das ações e relações cotidianas, por sua vez, é a que se manifesta no dia a dia, como nos ambientes religiosos, nos sindicatos, associação do bairro, ou movimentos sociais. Intrinsecamente as movimentações políticas da esfera cotidiana influenciam-se mutuamente às ações dos organismos de Estado, este que por sua vez tende a agir para atender às demandas sociais.

As ações da política de Estado que buscam atender estas demandas sociais, são organizadas e implementadas por meio de políticas públicas (Mainardes, 2018), que podem ter diferentes objetivos e atender áreas sociais distintas, como educação, saúde e segurança. Estas políticas públicas são norteadoras da atuação estatal, pois determinam "[...] 'o que fazer' [...], 'aonde chegar' [...] e 'como fazer [...]'” (Rodrigues, 2010, p. 52-53). Dentre os campos de atuação com políticas públicas do Estado brasileiro, a educação ganha destaque, devido, principalmente, à sua reconhecida importância na formação humana, à grande demanda populacional e às determinações constitucionais.

A educação tem tal notoriedade no campo das políticas públicas brasileiras, por se impor como um fator essencial ao desenvolvimento de qualquer sociedade, fornecendo as bases conceituais que podem qualificar a vida humana. Rego (2018), salienta que Educação pode ser compreendida por várias perspectivas, mas destaca duas concepções, uma em sentido amplo e outra em sentido estrito. Para o pesquisador, "[...] a educação, em sentido amplo, representa tudo aquilo que pode ser feito para desenvolver o ser humano e, no sentido estrito, representa a instrução e o desenvolvimento de competências e habi- 
lidades” (p. 39). Deste modo, podemos compreender que quando tratamos da educação escolar nos referimos a concepção de educação no sentido estrito. Essa concepção de educação se expressa na Carta Magna brasileira, em seu Artigo 205, ao definir que a "A educação, direito de todos e dever do Estado e da família [...]" deve visar "[...] o pleno desenvolvimento da pessoa, seu preparo para o exercício da cidadania e sua qualificação para o trabalho" (Brasil, 1988, p. 123).

Paralelamente são as crianças, os adolescentes e jovens, os grupos sociais etários que estão em fase de construção de referenciais e conhecimentos, que compõem principalmente o âmbito formativo do ensino fundamental, do ensino médio e da graduação. Em 2019, por exemplo, apenas na educação básica foram registradas "47,9 milhões de matrículas nas 180,6 mil escolas de educação básica no Brasil [...]” (Brasil, 2019, p.14), sendo que $80 \%$ desse contingente utiliza-se das redes públicas de ensino, conforme contabilizado pelo Censo da Educação Básica de 2019. As já conhecidas desigualdades sociais e regionais, potencializam a complexidade da educação brasileira.

Essa realidade dialoga no sentido de que a política educacional envolve o atendimento às demandas sociais por educação, servindo, assim, como uma "[...] ponte que liga as determinações e objetivos legais com a realidade local” (Ferreira; Nogueira, 2015, p. 102). Mainardes (2018, p. 188) adverte que em geral essas políticas "[...] são fragmentadas, pontuais e incompletas e constituem-se em instrumentos de poder simbólico sejam elas expressas na forma de textos legais ou discursos oficiais [...]" (2018, p. 188) e podem ser organizadas e implementadas pelas esferas municipal, estadual ou federal sempre em consonância com a hierarquia constitucional.

A hierarquia da política educacional brasileira se estrutura a partir da Constituição Federal (CF) de 1988. O documento previu a criação de um Sistema Nacional de Educação que deve articular-se a um plano decenal, bem como, delimita as competências de cada entidade federativa: a União, Estados Federados, e Municípios (Ferreira; Nogueira, 2015). Além disso, a CF determina no Art. 205, que a educação é "[...] direito de todos e dever do Estado e da família, será promovida e incentivada com a colaboração da sociedade [...]" (Brasil, 1988, p. 123).

A partir da promulgação da CF, desdobraram-se uma série de políticas que visam atender os objetivos educacionais propostos em 1988, em todas as esferas de poder, dentre as quais podemos elencar no âmbito das políticas Federais: a Lei de Diretrizes e Bases - LDB (1996); Fundo de Manutenção e Desenvolvimento do Ensino Fundamental e de Valorização do Magistério - FUNDEF (1996); Parâmetros Curriculares Nacionais - PCNs (1997); Exame Nacional do Ensino Médio - ENEM (1998); Programa Nacional de Transporte Escolar - PNATE (2004); Plano de Desenvolvimento da Escola - PDE (2007); Programa Nacional de Reestruturação e Aquisição de Equipamentos para a Rede Escolar Pública de Educação Infantil - PROINFÂNCIA (2007); Fundo de Manutenção e Desenvolvimento da Educação Básica - FUNDEB (2007); Sistema de Seleção Unificada - SISU (2010); Diretrizes Curriculares Nacionais - DCNs (2013); Base Nacional Comum Curri- 
cular - BNCC (2017/2018). Esse conjunto nacional de políticas, vai sendo atualizado de acordo com a realidade política do país e direciona as políticas dos estados membros e municípios.

É possível notar a complexidade das políticas educacionais, conforme apontado por Mainardes (2018). Também as distintas áreas da educação que cada política visa atender, e o processo de desenvolvimento do conjunto de documentos que compõem a política educacional brasileira. Assim, percebe-se que a política educacional não se mantém de forma estática, mas sim em uma constante transformação e renovação. Neste sentido Souza (2016) enfatiza que a política educacional é "[...] algo mais dinâmico e complexo do que a didática linearidade na qual por vezes gostaríamos de representá-la, onde o governante decide a política e para tanto age conforme seus valores e interesses [...]" (Souza, 2016, p. 84).

Esse conjunto legal que compõe a política educacional brasileira se estende para além do documento e se concretiza nos estabelecimentos de ensino. Ferreira e Nogueira (2015), argumentam que a política educacional tem como função, alterar uma realidade no interior da escola. Para os autores, essas alterações se expressam no campo da organização escolar, no desenvolvimento e no trabalho cotidiano da escola, bem como na prática pedagógica docente, o que concerne à política educacional a característica de alterar potencialmente a cultura escolar.

A concretização da política educacional nas instituições de ensino, infere em resultados e consequências, que são de caráter político, administrativo, organizacional e pedagógico. Esses resultados da política educacional, podem ser positivos ou negativos e atender, ou não, a demanda social que culminou na política, favorecer, ou não, um determinado grupo social, conforme argumenta Mainardes (2018). Deste modo, podemos entender que as demandas sociais por educação, que por vezes são demandas das instituições de ensino, inferem em políticas educacionais, que por sua vez, influem em consequências e resultados também nas instituições de ensino.

A figura 1 apresenta, por meio de um fluxograma, os principais elementos envolvidos nos processos de criação e implementação das políticas educacionais no Brasil, conforme debatido até aqui.

Podemos vislumbrar que as políticas educacionais são mecanismos do Estado, entremeados pelas disputas por poder dos grupos de interesses envolvidos, que buscam atender as demandas sociais por educação. A atuação do Estado para atender as demandas sociais por educação, muitas vezes, se realiza por meio de políticas públicas que são complexas, fragmentadas, pontuais, incompletas, mutáveis e aliançadas a seu espaço-tempo coetâneo. As políticas, por sua vez, inferem em resultados e consequências que se manifestam na realidade de maneira heterogênea. Os resultados e as consequências da política educacional, assim, interferem na realidade escolar e na sociedade como um todo, o que nos remete à relação de influência mútua, existente entre a realidade do espaço geográ- 
fico coetâneo e as políticas educacionais. Considerando que a política educacional influencia e é influenciada pela realidade do espaço, agora trazemos uma reflexão envolvendo a discussão da noção de espaço geográfico.

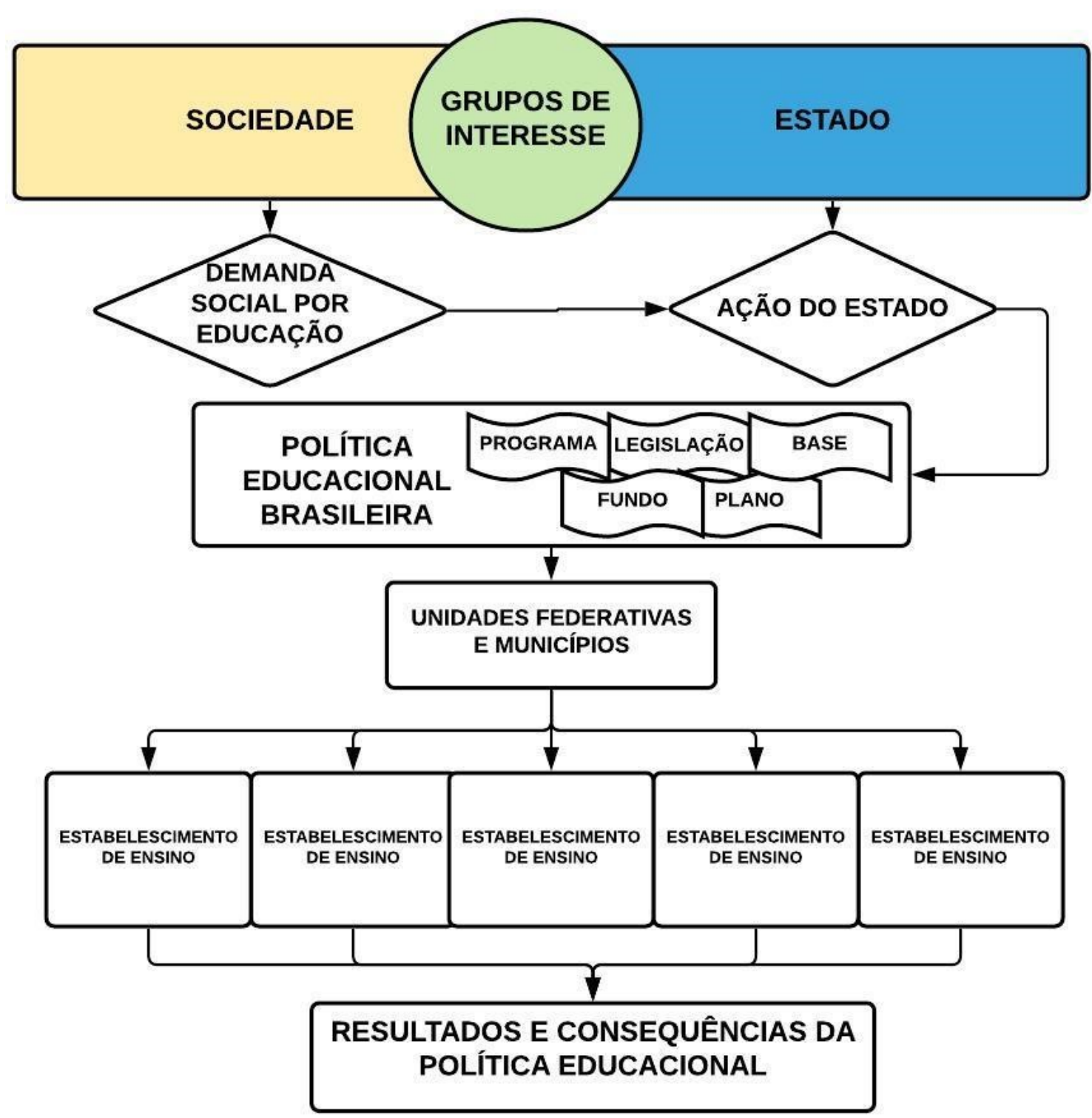

Figura 1 - Fluxograma Política Educacional. Fonte: Elaborado pelos autores, 2021.

\section{ESPAÇO GEOGRÁFICO COETÂNEO E LUGAR COTIDIANO}

Pensar numa perspectiva escalar geográfica ajuda a entender a relação entre a amplitude que destaca o todo imaginado e a singularidade da realidade. Pois ambas as visualizações são importantes para pensar o espaço geográfico e cada lugar que o compreende, para entender as relações entre produção e representação, e entre a generalidade conceitual e a realidade vivida. Neste sentido, cabe lembrar o que sugere Callai (2006, p. 94-95, destaque da autora) ao analisar a relação escalar geográfica: 
A escala de análise é um critério importante no estudo da Geografia. É fundamental que se considere sempre os vários níveis desta escala social de análise: "o local", o "regional", o "nacional" e o "mundial". A busca das explicações do que acontece em determinados níveis desta escala, em outras dimensões favorece análises mais conseqüentes [sic] [...] Há em cada um destes níveis, portanto, a presença dos demais.

Para Milton Santos (2006) o espaço geográfico é um híbrido do social e do físico, "[...] formado por um conjunto indissociável [...] de sistemas de objetos e sistemas de ações [...]" que são interdependentes e mutuamente influenciados (p. 39). Para o autor, o objeto pode ser compreendido como "[...] tudo o que existe na superfície da terra, toda herança da história natural e todo resultado da ação humana que se objetivou” (p. 46). São dotados de valor social, e são funcionais quando ligados a outros objetos, sendo necessária, portanto, a concepção de sistemas de objetos. Já os sistemas de ações se pautam nas relações sociais e na função dada à ação humana para criar e modificar os objetos.

Também, para Milton Santos, o humano e o tempo são indissociáveis na conceituação de espaço geográfico. O tempo, pois sempre "[...] o ponto de partida é a sociedade humana em processo, isto é, realizando-se" (p. 54), e o humano, pois é este quem confere aos objetos e ás ações, sentido, significado e funcionalidade.

Doreen Massey (2008) propõe, ainda, uma concepção de espaço geográfico coetâneo, um sistema aberto e inacabado, em constante construção, fruto das inter-relações contemporâneas heterogêneas em uma esfera de possibilidades da existência de multiplicidades. Assim, para a estudiosa, o espaço não é estático, mas pode ser compreendido como algo vivo, que se constrói e reconstrói segundo as inter-relações contemporâneas multiescalares e diversas do humano com outros humanos, e com o não humano. Também neste sentido, a autora argumenta que

[...] o espaço é a dimensão social não no sentido da sociabilidade exclusivamente humana, mas no sentido do envolvimento dentro de uma multiplicidade. Trata-se da esfera da produção contínua e da reconfiguração da heterogeneidade, sob todas as suas formas [...]" (2008, p. 97-98, destaque nosso).

Para a autora, é por meio do lugar cotidiano, este compreendido como a parcela singular do espaço em que se concretizam as vivências cotidianas, que os sujeitos se relacionam com outros sujeitos e lugares, e assim, interpretam, assimilam e constroem o mundo. Deste modo, Massey (2008) afirma que "[...] o que é especial sobre o lugar é, precisamente, esse acabar juntos, o inevitável desafio de negociar um aqui-e-agora [...], e a negociação que deve acontecer dentro e entre ambos, o humano e o não humano” (p. 203). É possível associarmos, portanto, com a concepção de lugar proposta por Milton Santos (2006), de que a conjunção de lugares e suas respectivas frações de sistemas resultam na totalidade do espaço geográfico. Nesse complexo, cada sujeito que está inserido, interpre- 
ta, constrói e modifica o espaço fragmentado por meio do seu lugar cotidiano, que é único, e que o liga ao mundo compondo a totalidade do espaço.

Santos (2006) também trata da ação humana, ao apontar que o ser humano age no espaço e no lugar de acordo com as suas necessidades se relacionando, modificando ou criando objetos, e essas necessidades podem ser "[...] materiais, imateriais, econômicas, sociais, culturais, morais, afetivas [...]” (p. 53), entre outras, e para atendê-las, a ação humana se pauta em razão e emoção. Neste sentido, o autor argumenta que a ação humana se concretiza no cotidiano de forma técnica, formal e simbólica, sendo essas formas de agir inseparáveis.

$\mathrm{O}$ agir técnico leva a interações formalmente requeridas pela técnica. $\mathrm{O}$ agir formal supõe obediência aos formalismos jurídicos econômicos e científicos. E [...] o agir simbólico, que não é regulado por cálculo e compreende formas afetivas, emotivas, rituais, determinadas pelos [sic] modelos gerais de significação e de representação. (2006, p. 53).

Deste modo, podemos compreender que o ser humano molda o espaço e os objetos à sua volta, e se relaciona com este espaço e outros humanos para atender suas diversas necessidades. Concomitantemente, é importante destacar que os objetos naturais e artificiais espaciais, também influenciam a ação e a vida humana, haja vista que esta é

[...] uma dimensão implícita que modula nossas cosmologias estruturantes. Ele modula nossos entendimentos do mundo, nossas atitudes frente aos outros, nossa política [...]. Afeta o modo como entendemos a globalização, como abordamos as cidades e desenvolvemos e praticamos um sentido de lugar (Massey, 2008, p. 15).

Denota-se que o espaço geográfico é concebido, mas é também percebido e vivido (Lefebvre, 2006, p. 99) associando "estreitamente, no espaço percebido, a realidade cotidiana." Portanto, o espaço geográfico, além de conceitualizado, é efetivamente vivido.

\subsection{O conceito vivido: imaginando um espaço geográfico coetâneo}

Propomos um exercício de imaginação para facilitar a associação dos conceitos e conhecimentos teóricos abordados sobre espaço geográfico, por Massey (2008) e Santos (2006), com um movimento multidimensional reflexivo acerca da realidade espacial cotidiana vivida. Poderíamos propor a reflexão sobre qualquer amplitude espacial geográfica, como um bairro, um conjunto habitacional ou um conglomerado empresarial, mas optamos pelo espaço escolar considerando a natureza deste artigo.

Pensando genericamente o espaço escolar atual, podemos visualizar uma série de objetos e ações que são característicos na maioria destes espaços escolares. Dentre os objetos, podemos pensar na estrutura predial, sendo este um objeto ao qual se destinada a função de abrigar a rotina escolar e suas materialidades, a mesa de estudos, a cadeira do 
estudante, o quadro, o armário, o livro didático, os materiais de educação física, os computadores do laboratório de informática, o apagador de lousa, as árvores, as rochas e o solo que servem como base a este espaço, por exemplo. Estes, e tantos outros objetos que possamos visualizar, estão ligados a uma série de outros objetos e possuem uma ou várias funções e interconexões entre si naquele local e no mundo. Eles não têm função quando isolados, e por isso, para além dos objetos, a escola possui um Sistema de Objetos. Há de se considerar que esta escola também está sujeita a uma herança natural, o espaço físico. O relevo do terreno escolar, o rio que abastece a escola, a arborização do lugar da escola, são heranças naturais únicas que se arranjam naquele local em que a escola se localiza, e também compõe os sistemas de objetos.

Concomitantemente podemos apontar uma série de ações características dos significados construídos neste espaço: a aula, as reuniões de planejamento e avaliação, a preparação de aulas e materiais, as formações docentes, o intervalo e toda sua complexidade, a reunião de pais e professores, a rifa escolar para angariar valores para a manutenção da escola, e tantas outras ações, que não ocorrem desassociadas ou sem motivo, e, portanto, podemos falar de um Sistema de Ações. Visando atender alguma necessidade das pessoas que ocupam este espaço, as ações dos sujeitos se pautam na técnica, quando pensamos em uma aula por exemplo, na formalidade quando pensamos na legislação a qual especificamente essa escola está sujeita, bem como o conjunto de conhecimentos científicos, ou nos simbolismos e emoções do cotidiano escolar.

Podemos entender que estas ações e estes objetos imaginados são indissociáveis, pois o espaço construído abriga a aula e a aula ocorre no espaço construído; na aula são usados os livros, as mesas e cadeiras de estudo; mas também, os livros, as cadeiras e as mesas de estudo são destinados às aulas. Também podemos compreender que este espaço é um híbrido (físico/social) que tem uma história, é a soma da herança natural da terra, com o que foi construído e modificado pela ação humana no decorrer do tempo. Percebese a inseparabilidade da natureza e sociedade na configuração desse lugar vivido, pois relevo, clima, vegetação e geologia, por exemplo, estão na base das estruturas físicas e das escolhas humanas. Mais do que isso, ele ainda está sendo (des)construído e modificado, não está pronto. O que é visível e perceptível hoje na escola, é fruto do que foi feito neste espaço no dia anterior, quando foi realizada a pintura da estrutura predial, ou na semana anterior quando na reunião de pais e mestres definiu-se que os portões passariam a fechar mais cedo, ou na semana seguinte quando será votado no congresso um projeto de lei que altera o currículo da educação básica. Ele também é fruto do que os seres humanos que viveram neste espaço construíram, e dos que vivem agora (des)constroem.

Essa escola também não está isolada do mundo, mas está ligada a uma série de outros espaços e pessoas, para além do território escolar. A escola influencia, por exemplo, o estudante a não descartar incorretamente seus resíduos, e esse conhecimento chega na casa do estudante tendo efeitos para além dos muros escolares, entre tantas outras possibilidades imagináveis. Ao mesmo tempo, os conhecimentos prévios que este estudante carrega 
consigo, o aumento no preço do dólar, a escolha política do/a diretor/a, um evento climático extremo, uma política educacional, impactam a realidade escolar. Esta escola é um fragmento do espaço, que está ligado ao mundo, e a este influencia, e por ele é influenciado.

Mas vejamos bem, cada escola é única. Algumas são de barro, outras de concreto; em algumas as aulas são pontuais e frequentes, já em outras sequer há professor; algumas atendem 1.000 estudantes, outras 10; algumas têm ar condicionado, outras não tem nem luz elétrica; algumas são urbanas, outras rurais. Cada escola é única, pois está em um espaço único, e foi construída e modificada (e continua sendo) por pessoas únicas, visando atender necessidades únicas, resultando na coetaneidade do espaço.

Podemos inferir, portanto, que essa escola imaginada é real. Ela é feita por gente que percebe, concebe e vive (Lefebvre, 2006) e, ao mesmo tempo que é produto, contribui para a produção da realidade coetânea. Isso, é espaço geográfico dialético-dialógico que se realiza por meio de confroencontros (Andreis, 2014) das multiplicidades coexistentes. Influenciada e influenciadora, constrói-se pelas interações ativamente, afirmando e acolhendo, resistindo e obstaculizando, os complexos regulamentos documentais da política educacional.

\section{O CONFROENCONTRO DA POLIITICA PÚBLICA EDUCACIONAL E DO ESPAÇO COETÂNEO}

Como já abordado, podemos compreender com base em Santos (2006) e Massey (2008) que o espaço geográfico é o conjunto indissociável de um sistema de objetos e um sistema de ações, em constante (des)construção, e é uma multiescalaridade em uma esfera de multiplicidades coetâneas. Também, que a política educacional brasileira, fragmentada e complexa, é fruto das demandas sociais por educação, gerando resultados e consequências na sociedade.

É nítida, neste sentido, a interinfluência cíclica existente entre estes dois conceitos que, por meio do confrontoencontro efetivo, diariamente constroem a realidade educacional. Ao mesmo tempo que a instituição de ensino compreende o sistema de objetos, ela atua por meio do sistema de ações. Assim, ela é impactada pelas ações do Estado, pois a ele é subordinada. Concomitantemente, é no espaço escolar, ou na vida em sociedade que surgem as demandas por educação resultantes na criação e implementação de políticas educacionais que alteram em algum grau a dinâmica do espaço onde gerou-se a demanda.

Assim, a política educacional não corresponde somente a um sistema de ações, mas também a um sistema de objetos, pois materializa no espaço resultados e consequências. Isto é, como exemplo, a BNCC, não é só um documento normativo estatal brasileiro, ela compõe o sistema de ações por se tratar de uma normativa, mas a sua existência e imple- 
mentação desdobram-se em consequências e resultados práticos e empíricos, alterando em algum grau a materialidade do sistema de objetos, e, portanto, compõe a este também, pois resulta na criação, modificação e uso do sistema de objetos.

Por meio da Figura 2, apresentamos uma síntese visual dos entrecruzamentos abordados neste ensaio, a fim de explicitar o confroencontro existente entre o espaço-tempo coetâneo e a política educacional que constituem o lugar escolar.

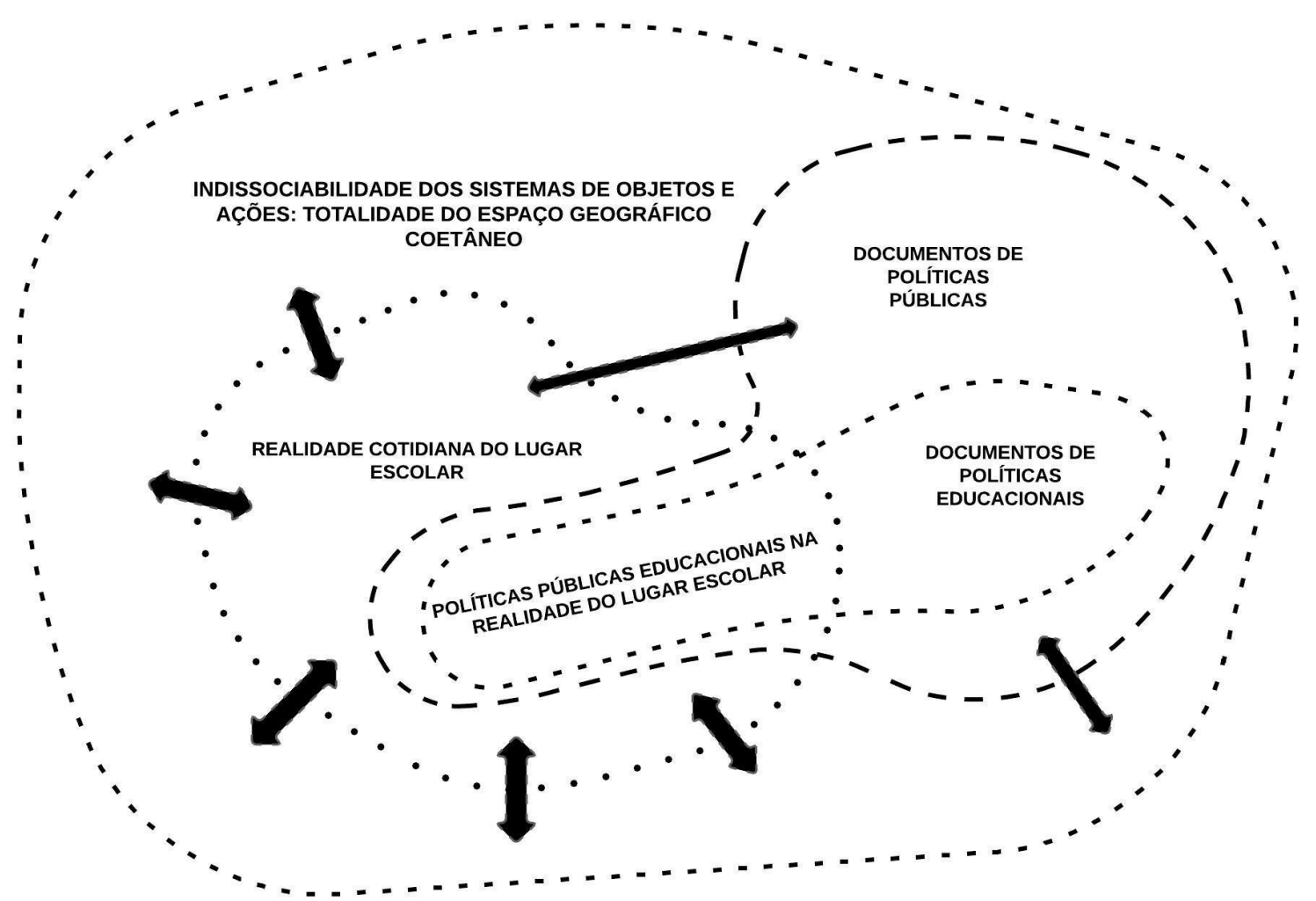

Figura 2: Confroencontros constitutivos do lugar escolar. Fonte: Elaborado pelos autores, 2021.

Na figura 2 expressamos os confroencontros, entendidos como sempre abertos, relacionais em construção, que estão presentes no lugar escola. Representa a apreensão dos conceitos que permeiam e se entrecruzam na construção desta discussão. A partir desta expressão também podemos propor algumas conclusões. Primeiramente alguns elementos da imagem precisam de uma apresentação, para explicitar a que se referem, pois as imagens e as palavras não abarcam a dialética dialógica que implica o contexto das interconexões constitutivas das políticas educacionais e do espaço geográfico. As linhas pontilhadas e tracejadas representam as interconexões permanentes e ilimitadas, entre realidade e documentos de política e o lugar e o global. "Paralelamente a essa multirrelacionalidade dos elementos geográficos, a interinfluência intrínseca a todos os conceitos representados diz respeito ao cuidado com a ideia da dimensão multirrelacional, uma vez 
que são elementos geográficos, e influenciam e são influenciados, o que também é representado/reforçado pelas setas. As formas geométricas irregulares utilizadas buscam representar ainda o constante devir e as singularidades: o devir, pois, tanto as políticas públicas educacionais como a realidade cotidiana do lugar escolar ou a totalidade do espaço, não estão finalizadas ou estáticas, mas sim em uma constante (des/re)construção; e as singularidades, pois cada elemento imageado é singular, e representam um espectro gigantesco de documentos e realidades singulares e multirrelacionais em (des/re)construção. Com estes elementos esclarecidos podemos partir para a interpretação da figura.

A totalidade do espaço geográfico representada é compreendida a partir das concepções de Massey (2008) e Santos (2006), envolvendo: a indissociabilidade dos sistemas de objetos e ações; a soma da herança natural da Terra com o que o humano objetifica e objetificou; o eterno devir; as multirrelacionalidades multiescalares do espaço-tempo coetâneo; e a conjunção de lugares singulares e suas respectivas frações de sistemas. Como já abordado, as políticas públicas e as políticas educacionais não são elementos dissociáveis da compreensão de espaço geográfico, uma vez que estes compõem tanto o sistema de ações por meio das normas, como o sistema de objetos pelo que materializam como resultados e consequências nos lugares. Deste modo, a totalidade do espaço compreende todos os elementos em estudo neste ensaio, e assim, é representada na figura.

As políticas educacionais, que envolvem os documentos de política, concretizam-se por meio dos confrontos e encontros com a realidade cotidiana do lugar escolar. Nesse complexo, a deliberação assume formas e consonância com as singularizações espaciais que se realizam no âmbito da vivência cotidiana. Deste modo, o lugar escolar não é representado na imagem enquanto centro, aliás, não centralizamos e atribuímos força a todos os entes implicados. Pois a figura, apresenta justamente o confroencontro que constitui o lugar escolar: da totalidade do espaço e da realidade cotidiana do lugar singular escolar com as deliberações documentais que regem e normatizam este espaço. Para além da constituição do lugar, a figura representa, também, a força do lugar em remodelar as deliberações de Estado em acordo com suas singularidades, de modo, que neste confroencontro se constitui o lugar escolar, mas também, se constitui a política educacional efetivamente como realidade.

A política educacional se realiza no tempo sendo constantemente desenvolvida e modificada, uma vez que não se trata de uma ferramenta estática, mas responde às necessidades de uma sociedade em seu espaço-tempo, e concomitantemente se impõe. Portanto, a política educacional é influenciada pela realidade do espaço, considerando que é criada por demandas socioespaciais (demandas sociais que sempre estão vinculadas às especificidades dos lugares), e ao mesmo tempo o influencia, pois modifica o espaço, tornando-se uma realidade socioespacial. Entretanto, é válido ressaltar que nem toda demanda social é democrática, isto é, uma demanda de um grupo social de influência política que seja atendida, pode não corresponder às necessidades ou reivindicações de uma maioria. 
A pandemia da COVID-19 em curso desde o início de 2020, causada pelo vírus SARSCov-2, permite denotar indícios de como esta singularidade dos lugares se impõe interinfluenciando fortemente as políticas educacionais relativas à pandemia. Em diversos municípios do Brasil e do mundo, escolas tiveram de se reinventar para atender aos desafios impostos pela pandemia, pela necessidade de isolamento social e pelo ensino remoto emergencial (Saviani; Galvão, 2021). Essa adaptação não ocorreu de maneira homogênea, unificada e coordenada, mas cada estado, município e escola encontra movimentos específicos para articular de modo único a realidade da vida do lugar às deliberações regulamentadoras e legitimadoras das ações escolares. Para Saviani e Galvão (2021), isso se deve ao descaso do governo federal, e à singularidade de cada lugar e infraestrutura escolar, cada público alvo, cada grupo de profissionais, e cada lugar em que a escola se encontra.

Cabe apontar que inexistem lugares iguais, então, não é possível que o sistema educacional do Brasil, com a multiplicidade diversa de escolas, profissionais e estudantes que envolve, consiga estabelecer um plano de ação que seja meramente aplicado de maneira igual em todas as escolas. Por maiores que sejam os esforços de um Estado em implementar igualmente uma política pública em todos os lugares sem considerar suas especificidades, ao se deparar com as diversas realidades dos lugares de implementação, essa política será recebida, interpretada e executada de modo específico em cada um destes. Nem mesmo enquanto regra geral, pois em alguns casos elas se tornam simplesmente inócuas, uma vez que, por exemplo, frente à determinação de voltar ao presencial, como ocorreu em março de 2021 em Santa Catarina, torna-se inviável, pois os sistemas de transportes são exíguos, especialmente, para aqueles que precisam se deslocar de outros municípios. Paralelamente, crianças e adolescentes não são controláveis com regras duras, como as proferidas nos planos de contingência para a COVID-19. Do mesmo modo, já é evidente que com grandes grupos de pessoas circulando e interagindo, os riscos de contaminação aumentam substancialmente. Ainda podemos questionar: uma escola da rede pública que convive com um laboratório de informática, salas informatizadas e equipadas eletronicamente, e professores adaptados a estas tecnologias, recebe da mesma forma a imposição do ensino remoto da pandemia que uma escola que sequer possui acesso à rede de energia elétrica? Certamente não. Cada lugar em suas singularidades, interage com esta política de modo específico.

Esses aspectos servem como indicativo para entender que o lugar se impõe nas políticas, ao mesmo tempo que as políticas tentam se impor aos lugares. Como podemos observar no Brasil afora as imposições e o empenho para o retorno às aulas presenciais, mesmo com uma pequena parcela da população já vacinada, nos Pareceres do Conselho Nacional de Educação e dos Conselhos Estaduais de Educação, nos Planos de Contingências Escolares, Decretos municipais, estaduais e federais, e outros documentos legais produzidos durante a pandemia. 
Mas, como demonstramos neste ensaio, essa realidade não se restringe ao período de pandemia. Este contexto somente exemplifica a inter-relação permanente entre políticas educacionais e o espaço geográfico. Todo o complexo de documentos deliberativos de posturas e atitudes no âmbito da educação, que compreendem a política educacional brasileira que é legitimada pelas interconexões com o espaço geográfico.

Assim, compreendemos que a política educacional se realiza em confroencontro com o espaço coetâneo promovendo resultados e consequências que são também espaciais e se manifestam no lugar, sobretudo o escolar, mas não somente neste. Os efeitos de uma mudança na política educacional (ou não) se materializam primeiramente no espaço escolar (e no lugar escolar), e neste com maior clareza, entretanto, toda a sociedade e a totalidade espacial, é impactada em algum grau, com os resultados de uma política.

Por fim, este ensaio permite inferirmos a relevância de compreender a interlocução inseparável entre espaço geográfico e política educacional. Tratá-las de modo estanque contribui para obstaculizar o enfrentamento dos desafios coetâneos, que cada vez mais escancaram as multiplicidades e diversidades coexistentes. Também, evidencia-se a necessidade de considerar as especificidades singulares de cada lugar na elaboração e implementação das políticas públicas, sobretudo as educacionais, pois de qualquer modo o lugar irá se impor na implementação, execução e interpretação da política na realidade. $\mathrm{O}$ espaço, não sendo uma concretude homogênea, mas sim, um entrecruzamento de lugares singulares, não pode ser regido, organizado e administrado a partir de políticas que o concebem de maneira diferente da heterogeneidade que a ele é intrínseca.

\section{REFERÊNCIAS}

ANDREIS, A. (2014): A aula: um território produto-produtor de espaço. Barcelona: XIII Coloquio Internacional de Geocrítica El control del espacio y los espacios de control Barcelona, p. 5-10.

BRASIL. (1988): Constituição da República Federativa do Brasil. Brasília, DF: Senado Federal.

BRASIL. (2019): Censo escolar da educação básica. Brasília, DF: INEP.

CALLAI, H. (2006): "Estudar o lugar para estudar o mundo". In: CASTROGIOVANNI, A. C. (Org.). Ensino de geografia, práticas e textualizações no cotidiano. Porto Alegre: Mediação, 2002. p. 83-134.

FERREIRA, L.; NOGUEIRA, F. (2015): Impactos das políticas educacionais no cotidiano das escolas públicas e o plano nacional de educação. Belo Horizonte: @ rquivo Brasileiro de Educação, v. 3, n. 5, p. 102-129. 
LEFEBVRE, H. (2006): A produção do espaço. Trad. Doralice Barros Pereira e Sérgio Martins (do original: La production de l'espace. 4e éd. Paris: Éditions Anthropos, 2000).

MAAR, W. (2017): O que é política?. Brasília: Editora Brasiliense.

MAINARDES, J. (2018): Reflexões sobre o objeto de estudo da política educacional. Sorocaba: Laplage em revista, v. 4, n. 1, p. 186-201.

MASSEY, D. (2008): Pelo espaço: uma nova política da espacialidade. Rio de Janeiro: Bertrand Brasil.

MELAZZO, E. (2010): Problematizando o conceito de políticas públicas: desafios à análise e à prática do planejamento e da gestão. Presidente Prudente: Revista Tópos, v. 4, n. 2, p. 9-32, 2010.

REGO, A. (2018): Educação: conceitos, finalidades e modalidades. Caxias do Sul: Scientia cum Industria, v. 6, n. 1.

RODRIGUES, M. (2010): Políticas públicas. São Paulo: Publifolha.

SANTOS, M. (2006): A natureza do espaço: técnica e tempo, razão e emoção. São Paulo: Edusp.

SAVIANI, D.; GALVÃO, A. (2021): Educação na Pandemia: a falácia do 'ensino remoto'. Boa Vista: Universidade e Sociedade ANDES-SN.

SOUZA, A. (2016): A política educacional e seus objetos de estudo. Brasil: Revista de estúdios teóricos y epistemológicos en política educativa, v. 1, n. 1, p. 75-89. 